\title{
O processo de reutilização da casca do arroz: um estudo de caso na empresa J. Fighera \& cia. Ltda
}

\author{
Jenesca Cechin', Thiago Kader Rajeh Ibdaiwi ${ }^{2}$, Damiana Machado de Almeida ${ }^{3}$, Vania Medianeira Flores \\ Costa ${ }^{4}$, Luis Felipe Dias Lopes ${ }^{5}$, Rita de Cássia Trindade dos Santos ${ }^{6}$ \\ 'Bacharel em Administração com Habilitação em Comércio Exterior - FAMES - Santa Maria, RS - Brasil \\ ${ }^{2}$ Professor na Faculdade Metodista de Santa Maria - FAMES - Santa Maria, RS - Brasil \\ ${ }^{3}$ Mestranda em Administração - PPGA/UFSM - Santa Maria, RS - Brasil \\ ${ }^{4}$ Professora Adjunta do Departamento de Ciências Administrativas da UFSM - Santa Maria, RS - Brasil \\ ${ }^{5}$ Professor Associado 2 da Universidade Federal de Santa Maria - Santa Maria, RS - Brasil \\ ${ }^{6}$ Acadêmica do Curso de Administração da Universidade Federal de Santa Maria - Santa Maria, RS - Brasil
}

\begin{abstract}
Resumo
Embora o tema Responsabilidade Social e Ambiental ainda seja desafiador, várias empresas procuram meios de preservação ambiental e ecológica com o propósito de se destacar no mercado. O presente artigo apresenta o processo de reutilização da casca do arroz na Empresa J. Fighera \& Cia Ltda em Santa Maria - RS. A pesquisa se caracteriza como descritiva de cunho bibliográfica e com pressupostos de estudo de caso. Os resultados comprovam que o referido engenho de arroz está preocupado com as questões ambientais e, por isso, já adota medidas tais como reutilizar a casca para fazer fogo nas fornalhas da secadeira, vender o restante do resíduo para olarias, baias e aviários. Sugere-se que a empresa faça parcerias com indústrias madeireiras. Conclui-se que a preocupação ambiental, é um dos passos fundamentais para toda empresa que almeja a eficácia, a excelência organizacional e que deseja ser referência na sociedade moderna.
\end{abstract}

Palavras-chave: Casca de Arroz, Gestão Ambiental, Reutilização de Resíduos.

\begin{abstract}
Although the theme Social and Environmental Responsibility is still challenging, many companies are seeking ways to preserve environmental and ecological in order to stand out in the market. This article presents the process of reuse rice husk in Company J. Fighera \& Cia Ltda in Santa Maria - RS. The research is characterized as descriptive nature of literature and case study assumptions. The results prove that the said rice mill is concerned with environmental issues and therefore already adopted measures such as reusing the shell to fire the furnaces of tedder, sell the remaining residue for pottery, pens and aviaries. It is suggested that the company make partnerships with timber industries. We conclude that environmental concern is a fundamental step for any company that wishes effectiveness, organizational excellence and wants to be benchmark in modern society.
\end{abstract}

Key-words: Rice husk, Environmental Management, Waste Reuse. 


\section{INTRODUÇÃO}

O campo de competição entre as organizações está cada vez mais acirrado e exigindo dessas um investimento em instrumentos importantes para esse processo de concorrência, tais como: comunicação eficiente, táticas de marketing, aperfeiçoamento na qualidade dos bens e serviços, inovação, criatividade, reaproveitamento de resíduos, entre outros. Neste sentido, para ter diferencial no mercado de trabalho, as empresas optam por estratégias que proporcionam uma maior retenção e satisfação de seus clientes, pois são eles os autores que sustentam os diferentes nichos mercadológicos.

Pode-se dizer que, ter cuidados ambientais também é sinônimo de competitividade, porque tal atitude pode atrair consumidores conscientes, além de se adequar às especificações legais exigentes. Para tanto, certas empresas estão tomando decisões imediatas para que possam se adaptar, o mais rápido possível, às tendências e consequentemente ampliar sua participação no seu nicho de atuação.

Uma das estratégias para ser referência empresarial diz respeito à Responsabilidade Social e Ambiental. Embora o tema ainda seja desafiador, várias empresas procuram meios de preservação ambiental e ecológica com o propósito de se destacar no mercado dos negócios agregando valor aos seus produtos. Atrelado a isto, também é possível aumentar a lucratividade através da gestão dos resíduos oriundos da produção, a exemplo disso, cita-se o grande potencial da reutilização da casca do arroz para a geração de resultados, como fonte geradora de energia alternativa, o que já vem sendo realizado por diversos segmentos de mercado.

O Rio Grande do Sul é atualmente o maior produtor de arroz em casca do Brasil, e chegou a registrar em 2011 a produção de 8.940.432 toneladas do grão. Considerando a última década, pode-se afirmar que o Estado aumentou consideravelmente a quantidade produzida, passando de uma média de 5.241.216 toneladas no período de 2000-2002 para uma média de 7.931.132 no período 20092011, de acordo com o Atlas Socioeconômico do Rio Grande do Sul (SEPLAG, 2013).

Segundo dados do IBGE, em 2012 o Rio Grande do Sul foi responsável por aproximadamente $65.3 \%$ da produção nacional de arroz. Assim como as empresas investem em melhorias, o setor agrícola também avança no desenvolvimento das lavouras, com o propósito de aumentar a ceifa ano após ano. Se as condições climáticas permitirem, a intenção dos agricultores é progredir e colher ainda mais na próxima safra. Aumentando a produção, obviamente haverá um aumento proporcional de resíduos do cereal, no caso, a casca de arroz (IBGE, 2012).

Entretanto, apesar da expressiva quantidade produzida, pouco se utiliza da casca desse cereal para fabricação de outros produtos ou com finalidades de gerar ganhos para os engenhos e até mesmo como uma boa alternativa de renda aos produtores. Apesar desse elevado índice de produtividade, são poucas as estratégias referentes ao processo de reutilização desses resíduos/ detritos. Nesta perspectiva, é necessário inovar e criar novas maneiras para reaproveitar tais detritos. Dessa forma, o presente estudo visa responder a seguinte problemática: Quais as alternativas de reutilização da casca do arroz, que podem gerar novas oportunidades de negócio para o Engenho de Arroz J. Fighera \& Cia. Ltda.? Tal questionamento nos remete ao seguinte objetivo: identificar as possíveis formas de reutilização da casca do arroz, capazes de gerar ganho.

Assim, a importância desse trabalho se dá tanto para as empresas quanto para a comunidade em geral. Para as empresas essa ideia é uma estratégia inovadora, que pode gerar oportunidades muito além da rentabilidade. Já, para a comunidade, o presente estudo menciona uma das medidas que pode beneficiar a conservação e preservação ambiental. No âmbito acadêmico, este trabalho também é relevante, pois contribui com informações acerca da orizicultura, fonte de renda de inúmeras famílias gaúchas. Inclusive, também proporciona uma visão mais ampla deste mercado de atuação e suas tendências, além de enriquecer os conhecimentos, unindo teoria e prática.

\section{REVISÃO DA LITERATURA}

Neste tópico do trabalho serão abordados os conteúdos que nortearam o presente estudo, com o intuito de construir um arcabouço teórico. Para melhor desenvolver a temática deste estudo optou-se por subdividir este capítulo em: Gestão Ambiental e seus Princípios; O Marketing Verde e a Rotulagem Ambiental e Produção de Arroz.

\section{I Gestão Ambiental e seus Princípios}

O comprometimento empresarial com questões ambientais que emergem de uma sociedade cada vez mais preocupada com o equilíbrio ecológico é, a longo prazo, um diferencial importante para o sucesso empresarial por proporcionar uma maior competitividade perante o mercado. Andrade, Tachizawa e Carvalho (2002, p.198) enfatizam que 
"com a globalização da economia e a internacionalização dos mercados, as preocupações mundiais se deslocam para a questão do meio ambiente".

De uma forma mais genérica para Barbieri (2004, p.2) o "meio ambiente é tudo o que envolve ou cerca os seres vivos". Ou seja, ele é um conjunto de fatores naturais, sociais e, inclusive culturais que influencia diretamente tudo o que o existe no planeta. Philippi e Pelicioni (2005, p.15) sustentam que "desde o aparecimento da forma mais primitiva de vida na Terra, o planeta vem sofrendo alterações". Porém, outros autores dizem que um dos principais focos de disseminação da degradação ambiental foi a Revolução Industrial no século XVIII. A partir desse momento, a mão-de-obra foi substituída pelas máquinas, havendo assim, uma maior proliferação de poluentes oriundos das atividades industriais. Tal Revolução teve como cenário inicial a Inglaterra, sendo que, imediatamente, se alastrou pelos demais recantos do mundo.

Para Dias (2006) o homem desenvolveu tecnologias, aperfeiçoou as estratégias para aumentar a produção, porém, avançou também na deterioração dos ecossistemas, provocando profundas alterações no meio ambiente, tais como: concentração da população nos centros urbanos, excessivo consumo de produtos não renováveis, desflorestamento, contaminação das águas, dos solos, do ar, entre outras implicações. Com o propósito de minimizar as consequências, a Gestão Ambiental ocupa um espaço na sociedade contemporânea, com o objetivo de rever e instigar algumas práticas que prejudicam o Planeta Terra. A Gestão Ambiental é uma parte da gestão global que está vinculada aos impactos do meio ambiente, aos objetivos e as metas ambientais, além de se relacionar com a política ambiental das empresas. Conforme Barbieri (2004, p.137), "entende-se por gestão ambiental empresarial as diferentes atividades administrativas e operacionais realizadas pela empresa para abordar problemas ambientais decorrentes da sua atuação ou para evitar que eles ocorram no futuro".

Dias (2006, p.11) menciona que "a problemática ambiental hoje faz parte da pauta obrigatória da maior parte dos encontros mundiais e torna-se uma preocupação crescente da maioria das empresas que não querem continuar fazendo o papel de vilãs da sociedade". Diante do exposto, é evidente que tanto pessoas físicas quanto jurídicas estão preocupadas com o referido assunto. Todos estão direcionando os olhares para os ecossistemas, para as questões ambientais, pois o ser humano e as demais espécies dependem, e muito, da natureza e de um ambiente saudável para viver equilibradamente. Segundo Bulos (2003, p.1353), isto também é ratificado pela Lei n. 6.938/81, pois conforme o art. 225 da Constituição Federal Brasileira de 1988 "todos têm direito ao meio ambiente ecologicamente equilibrado, bem de uso comum do povo e essencial à sadia qualidade de vida, impondo-se ao Poder Público e à coletividade o dever de defendê-lo e preservá-lo para as presentes e futuras gerações".

Segundo Donaire (2009, p.13),

Nas últimas décadas tem ocorrido uma mudança muito grande no ambiente em que as empresas operam: as empresas que eram vistas apenas como instituições econômicas com responsabilidades referentes a resolver os problemas econômicos fundamentais (o que produzir, como produzir e para quem produzir) têm presenciado o surgimento de novos papéis que devem ser desempenhados, como resultado das alterações no ambiente em que operam.

Conforme salienta Coimbra (1985) as organizações, aos poucos, estão dando ênfase na Gestão Ambiental, com o intuito de diminuir os impactos provenientes da industrialização, ao qual alteram o espaço ambiental. Para um melhor entendimento do que realmente é a Gestão Ambiental, é relevante conceituar, primeiramente, o que é o meio ambiente:

Conjunto de elementos físico-químicos, ecossistemas naturais e sociais em que se insere o homem, individual ou socialmente, num processo de interação que atenda ao desenvolvimento das atividades humanas, à preservação dos recursos naturais e das características essenciais do entorno, dentro dos padrões de qualidade definidos (p.29).

Na visão dos autores Andrade, Tachizawa e Carvalho (2002, p.214),

A gestão ambiental é a resposta natural das empresas ao novo cliente, o consumidor verde e ecologicamente correto. A empresa verde é sinônimo de bons negócios e, no futuro, será a única forma de empreender negócios de forma duradoura e lucrativa. Em outras palavras, o quanto antes as organizações começarem a enxergar o meio ambiente como seu principal desafio e como oportunidade competitiva, maior será a chance de que sobrevivam. 
Pelo exposto infere-se que as empresas precisam atender a esta nova demanda do mercado, cujo cliente está associando os produtos com a imagem ecológica. É evidente que o aumento da produtividade e a redução dos custos também estão interligados com o meio ambiente, porque é por meio deste que se obtém grande parte das matérias-primas para a produção de bens de consumo, ou seja, o ser humano interfere diretamente na natureza. Assim, a Gestão Ambiental pode amenizar depredações ecológicas por meio da reutilização de resíduos, da reciclagem, a partir da inovação e da criatividade, com o propósito de haver uma maior preservação ambiental. Além disso, é importante ressaltar que na atmosfera não há somente bens renováveis. Por isso, a ideia de reaproveitar certos materiais são métodos alternativos que integram os cuidados ambientais, e para que isso ocorra é necessário trabalhar com ideias inovadoras.

\subsection{O Marketing Verde e a Rotulagem Ambiental}

Segundo Kotler (2003) a identificação das necessidades e desejos insatisfeitos para a especificação de um mercado-alvo é a função empresarial do marketing que a partir de um potencial de rentabilidade decide sobre novos produtos, serviços e programas adequados para servir a esses mercados selecionados, configurando-se como um instrumento articulador dentro da organização para pensar no cliente e atender ao cliente.

Conforme Baker (2005) o marketing, por sua vez, também possui diversos ramos. O marketing ambiental, conhecido também como marketing verde ou ecomarketing, é representado pelos esforços das empresas em satisfazer às expectativas dos consumidores por produtos que determinem menores impactos ambientais ao longo de seu ciclo de vida - produção, embalagem, consumo, descarte - e a divulgação de tais esforços de modo a gerar mais consumo desses produtos e, consequentemente, maiores lucros para as organizações.

Ligado ao marketing ambiental, também está se consolidando no mercado os rótulos ambientais, mais conhecidos como selos verdes que denotam uma característica ambientalista no produto que está sendo comercializado. "Os selos ou rótulos ambientais visam informar os consumidores ou usuários sobre as características benéficas ao meio ambiente presentes em produto ou serviço específicos, tais como biodegrabilidade, retornabilidade, uso de material reciclado, eficiência energética e outras" (BARBIERI, 2004, p.147).

Assim conforme Dias (2006) a inovação torna-se um pré-requisito muito importante para adequação e pró-atividade empresarial perante as exigências do contexto, configurando-se a rotulagem ambiental como um forte recurso que assegura ao consumidor a incorporação da variável ecológica nos produtos.

Com o aumento da consciência ambiental em todo o mundo, está consolidando-se um novo tipo de consumidores, chamados "verdes", que faz com que a preocupação com o meio ambiente não seja somente um importante fato social, mas seja considerado também como um fenômeno de marketing novo (p.139).

Neste sentido, Tachizawa (2009, p.76) explica que "um dos efeitos da competição global foi o redirecionamento do poder para as mãos do comprador". Nota-se, então, que a população precisa se conscientizar a respeito do paradigma ambiental, e o consumidor, cada vez mais exigente, opta por itens que possuem a rotulagem ambiental, porque o selo verde é um alvo procurado por pessoas que incentivam a preservação do meio ambiente. Para tanto, as empresas se aliam junto aos seus clientes e, aos poucos, se demonstram favoráveis na propagação do marketing ambiental.

Desta maneira, nota-se que a rotulagem ambiental é um certificado que busca promover os produtos, auferindo-os uma qualidade ambiental, tornando-os, desta forma, superior a outros produtos de mesma classe. Seus principais objetivos são: sensibilizar os consumidores, proporcionar informações exatas e aprimorar a imagem do produto. No Brasil, o estabelecimento do selo verde se deu no ano de 1990, quando a Associação Brasileira de Normas Técnicas (ABNT) propôs a implementação de uma ação conjunta ao Instituto Brasileiro de Proteção Ambiental (TACHIZAWA, 2009).

Vários são os produtos que possuem o selo verde. Inclusive, o setor agrícola também já adotou este método. O Instituto Rio Grandense do Arroz, em 2008, lançou o selo de responsabilidade socioambiental para fomentar as práticas agrícolas, com o propósito de aumentar a produção, reduzir o desperdício de fertilizantes e da água, além de diminuir a geração de resíduos (REVISTA CAMPO ABERTO, 2009). Já para a safra de 2011/2012 o governo do estado do Rio Grande do Sul regulamentou, através do IRGA, em conformidade com a Secretaria Estadual de Agricultura, Pecuária, Pesca e Agronegócio o selo ambiental da lavoura de arroz irrigado do Rio Grande do Sul, para os empreendimentos agrícolas produtores de arroz (REVISTA LAVOURA ARROZEIRA, 2009).

É importante mencionar que tanto pessoa 
física quanto jurídica pode incluir no produto arroz o selo ambiental, desde que realize o processo específico para a utilização do rótulo que consiste em três etapas: Habilitação, inscrição para cadastro junto ao IRGA; Auditoria, realizada pela Comissão Municipal de Avaliação por meio de vistorias técnicas e Julgamento, resultado da análise feita pela Comissão com posterior entrega do selo ambiental. Diante disso, percebe-se que são vários os fatores analisados para utilizar o rótulo verde. Todavia, este selo pode ser incluso nas embalagens do produto, como também, nas notas fiscais emitidas e nas correspondências da empresa agrícola e de seus produtores e agricultores (IRGA, 2012).

\subsection{A produção de arroz}

O arroz, cujo nome científico é Oryza Sativa, é um cereal explorado por todos os continentes e consumido mundialmente, por isso destaca-se por constituir a dieta básica da população. O referido grão faz parte da base alimentar de grandes contingentes humanos, tanto em regiões desenvolvidas quanto em desenvolvimento (PESKE, NEDEL e BARROS, 1998).

A produção do arroz ocorre de forma sazonal, ou seja, há uma temporada específica para o cultivo. Outubro e novembro é o período ideal para a plantação do cereal, e nos meses de março e abril do ano seguinte ocorre à colheita do grão. Porém, esta prática agrícola sofre com as influências climáticas, o que pode ocasionar atraso na semeadura e, portanto, na safra. Para que se possa ter uma melhor produção do cereal, o tipo de solo e seu manejo são aspectos fundamentais que visam maior fertilidade do grão. $\mathrm{O}$ arroz produzido em nosso país provém do sistema sequeiro e do sistema irrigado. $\mathrm{O}$ primeiro sistema mencionado é cultivado em terras altas e o outro sistema em várzeas (CONAB, 2011).

Segundo dados do Ministério da Agricultura, o Brasil é o nono maior produtor mundial de arroz e colheu 11,26 milhões de toneladas na safra 2009/2010. As projeções de produção e consumo de arroz, avaliadas pela Assessoria de Gestão Estratégica do Mapa mostram que o Brasil terá aumento anual da produção de 1,15\% nos próximos dez anos. O consumo deverá crescer a uma taxa média anual de $0,86 \%$, alcançando 14,37 milhões de toneladas em 2019/2020. Assim, a importação projetada para o final do período é de 652,85 mil toneladas. A taxa anual projetada para o consumo de arroz nos próximos anos, de $0,86 \%$, está pouco abaixo da expectativa de crescimento da população brasileira (MINISTÉRIO
DA AGRICULTURA, 2013).

Entre as unidades da federação, o Rio Grande do Sul é atualmente o maior produtor de arroz em casca do Brasil. No entanto, registrou pequenas oscilações principalmente por influência de algumas condições climáticas desfavoráveis, como por exemplo, períodos de estiagem prolongada, já que a cultura é altamente demandante de água para irrigação. Mas, com base na relação quantidades produzidas e área plantada, na última década, pode-se afirmar que houve importante ganho de produtividade no RS através de inovações técnicas, como por exemplo, no manejo dos solos e no uso de insumos e sementes de última geração, aliados às boas condições climáticas. A produção tem como destino o mercado interno e externo e é um dos itens de destaque na pauta de exportações gaúchas (SEPLAG, 2013).

Em análise realizada pela Secretaria de Planejamento, Gestão e Participação Cidadã, o Rio Grande do Sul foi destaque na produção média de arroz dentre os maiores estados produtores do Brasil no período de 2000 a 2011.

Portanto, no período analisado o Rio Grande do Sul apresenta um produtividade de arroz superior aos demais estados brasileiros produtores, chegando a ser responsável em média por 8.000 toneladas da produção do grão no ano de 2009 e 2011, em uma produção nacional total em torno de 12.000.000 de toneladas. Segundo dados do Instituto Rio Grandense do Arroz a safra 2012/2013 para o mês de maio de 2013 apresentou uma área colhida de 1.072.481 ha, com uma produtividade média de $7.433 \mathrm{~kg} / \mathrm{ha}$. Dentre as principais regiões produtoras, destaca-se a Fronteira Oeste com $30 \%$ da produção total e a região da Campanha e Depressão Central, ambas com 14\% da produção. A cidade de Santa Maria situada na Região da Depressão central contribuiu com $8 \%$ da produção regional.

Portanto, no período analisado o Rio Grande do Sul apresenta um produtividade de arroz superior aos demais estados brasileiros produtores, chegando a ser responsável em média por 8.000 toneladas da produção do grão no ano de 2009 e 2011, em uma produção nacional total em torno de 12.000.000 de toneladas. Segundo dados do Instituto Rio Grandense do Arroz a safra 2012/2013 para o mês de maio de 2013 apresentou uma área colhida de 1.072.481 ha, com uma produtividade média de $7.433 \mathrm{~kg} / \mathrm{ha}$. Dentre as principais regiões produtoras, destaca-se a Fronteira Oeste com $30 \%$ da produção total e a região da Campanha e Depressão Central, ambas com 14\% da produção. A cidade de Santa Maria situada na 


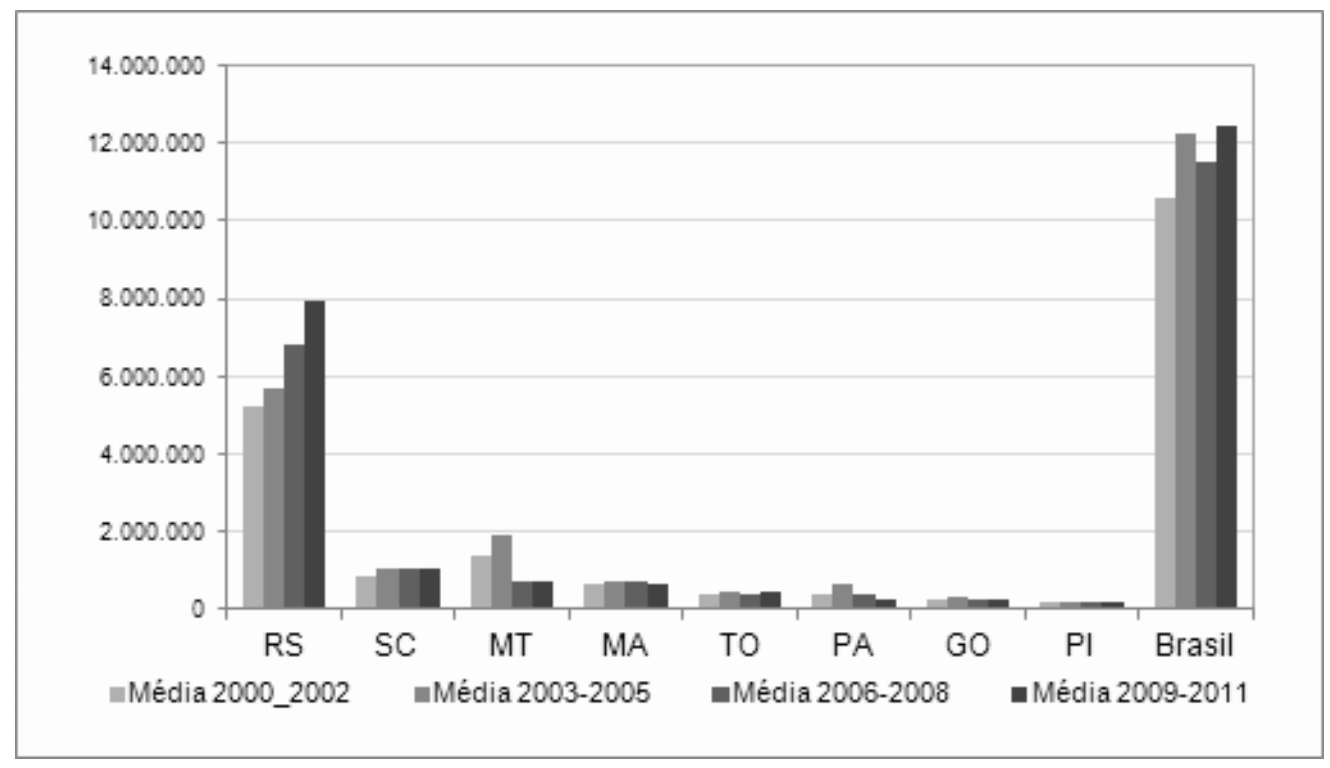

Figura 1 - Média da produção de arroz em casca no Brasil e nos maiores estados produtores no período de 2000 a 2011 (em toneladas) Fonte: SEPLAG (2013)

Região da Depressão central contribuiu com $8 \%$ da produção regional.

Diante desses dados, fica evidente que quanto maior é a produtividade, maior também será a quantidade de casca, oriunda do beneficiamento do arroz. Por isso, é de extrema importância que o Governo, as empresas, os produtores do grão e a sociedade em geral não se preocupem somente em aumentar a produtividade de cereais e sua comercialização, mas também, que demonstrem inquietação e busque alternativas para reutilizar os resíduos do arroz. Toda a indústria almeja prospecção nos negócios. Porém, por ser a protagonista da poluição ambiental, deve ter a incumbência de procurar metodologias inovadoras e praticá-las para combater a depredação do ecossistema.

Nesse contexto, inovar torna-se uma necessidade em resposta as demandas do mercado e da sociedade. De forma sucinta, há quem considere que inovação é a exploração bem sucedida de novas ideias. Segundo Drucker (2000, p.39), a inovação "é o instrumento específico dos empreendedores, o processo pelo qual eles exploram a mudança como uma oportunidade para um negócio diferente ou um serviço diferente".

Dentre as várias possibilidades de inovar, aquelas que se referem às inovações de produto ou de processo são conhecidas como inovações tecnológicas. Outros tipos de inovações podem se relacionar a novos mercados, novos modelos de negócio, novos processos e métodos organizacionais ou, até mesmo, novas fontes de suprimentos. Como exemplo, podemos utilizar Rogers e Shoe- maker (1971), pois argumentam que uma inovação pode ser uma nova ideia, uma nova prática ou também um novo material a ser utilizado em um determinado processo. Desta forma, podemos visualizar a inovação em diferentes naturezas, que podem ser refletidas em esquemas classificatórios, diferenciando-se entre inovações administrativas e técnicas (KIMBERLY e EVANISKO, 1981), inovação no trabalho organizacional, inovações em produtos e inovações em processos (WHIPP e CLARK, 1986).

\section{METODOLOGIA}

Um dos principais objetivos de uma pesquisa é obter respostas convincentes para os problemas propostos no estudo. Para tanto, é necessário desenvolver a pesquisa mediante os conhecimentos disponíveis e a cuidadosa utilização dos métodos, das técnicas e dos procedimentos científicos (GIL, 1996).

A metodologia trata das formas de se fazer ciência e tem a incumbência de cuidar das ferramentas, dos procedimentos e dos caminhos para realizar um trabalho (DEMO, 1987). Ou seja, a metodologia engloba todos os processos realizados na pesquisa.

Sendo assim, o presente estudo é caracterizado como pesquisa bibliográfica. Conforme Furasté (2008, p.33), ela "baseia-se fundamentalmente no manuseio de obras literárias, quer impressas, quer capturadas via internet". Para 
Oliveira (2001, p.119), "a pesquisa bibliográfica tem por finalidade conhecer as diferentes formas de contribuição científica que se realizaram sobre determinado assunto ou fenômeno". Além disso, tem o intuito de colocar o pesquisador em contato direto com tudo o que foi escrito sobre certo assunto (LAKATOS e MARCONI, 2007).

Este trabalho também é classificado como pesquisa descritiva, que segundo Cervo, Bervian e Silva (2007, p.61),

Observa, registra, analisa e correlaciona fatos ou fenômenos (variáveis) sem manipulá-los. Procura descobrir, com maior precisão possível, a frequência com que um fenômeno ocorre, sua relação e conexão com outros, sua natureza e suas características.

Na concepção de Gil (2008, p.42), a pesquisa descritiva "tem como objetivo primordial a descrição das características de determinada população ou fenômeno ou, então, o estabelecimento de relações entre variáveis".

Adotou-se também a forma de pesquisa exploratória, que na percepção de Severino (2007, p.123), este tipo de pesquisa "busca apenas levantar informações sobre determinado objeto, delimitando assim um campo de trabalho, mapeando condições de manifestação desse objeto". Contudo, Cervo, Bervian e Silva (2007, p.63) mencionam que "a pesquisa exploratória não requer a elaboração de hipóteses a serem testadas no trabalho, restringindo-se a definir objetivos e buscar mais informações sobre determinado assunto de estudo". Ainda nesta linha de pensamento, os autores afirmam que a pesquisa exploratória revela demonstrações precisas da situação, além de ter o propósito de averiguar as relações que existem entre os elementos componentes.

Este estudo, portanto, seguiu os pressupostos do estudo de caso. Nesta temática, Severino $(2007$, p.121) afirma que estudo de caso é a "pesquisa que se concentra no estudo de um caso particular, considerado representativo de um conjunto de casos análogos, por ele significativamente representativo". Na visão de Cervo, Bervian e Silva (2007, p.62), o referido delineamento "é a pesquisa sobre determinado indivíduo, família, grupos ou comunidade que seja representativo de seu universo, para examinar aspectos variados de sua vida".

Com o intuito de analisar e verificar as possíveis formas de reutilização da casca do arroz, capazes de gerar ganho, o presente estudo no Enge- nho de Arroz J. Fighera \& Cia Ltda compreendeu as seguintes etapas: (1) entrevista semiestruturada com o gestor do engenho; (2) questionário aplicado com os produtores/fornecedores de arroz; (3) e pesquisa bibliográfica com o objetivo de verificar na literatura outras alternativas que já estão sendo utilizadas pelos mais diversos segmentos.

Primeiramente, foi realizada entrevista semiestruturada com um gestor de engenho no intuito de verificar a percepção deste a respeito dos aspectos relacionados à produção e reutilização da casca de arroz.

No segundo momento foram aplicados questionários com os produtores/fornecedores de arroz de forma aleatória e não probabilística, inclusive, alguns são clientes da empresa. O instrumento utilizado para a coleta dos dados foi enviado pessoalmente e via correio eletrônico para 80 produtores/fornecedores de arroz. O retorno, por sua vez, superou as expectativas, pois todos devolveram o questionário. O número total, segundo o sindicato rural gira em torno de 400 produtores rurais. Levando em consideração este número (população) o número de pesquisados corresponde a amostragem de $20 \%$.

No terceiro momento, realizou-se uma pesquisa bibliográfica onde procurou-se fazer um levantamento em artigos e textos com o intuito de verificar as possibilidades de produção e reutilização da casca do arroz.

O método qualitativo também caracteriza o presente estudo. Segundo Martins e Bicudo (1994), enquanto o método qualitativo é baseado em falas, interpretações e opiniões, o quantitativo é fundamentado em números, tabelas, gráficos e quadros. A investigação qualitativa busca a compreensão peculiar do estudo, pois o foco é o específico, ou seja, não se preocupa com a generalização e as leis. Na percepção de Richardson (1999, p.90), "a pesquisa qualitativa pode ser caracterizada como a tentativa de uma compreensão detalhada dos significados e características situacionais apresentadas pelos entrevistados".

\section{RESULTADOS E DISCUSSÕES}

A seguir serão apresentados os resultados do estudo conforme objetivo proposto, bem como a discussão do mesmo com base na literatura pesquisada. Apresenta-se primeiramente uma breve descrição do perfil do gestor entrevistado na primeira etapa da pesquisa e os dados relativos à produção e reutilização da casca de arroz praticada atualmente pelo Engenho. Na sequência o perfil dos 
produtores/fornecedores pesquisados na segunda etapa da pesquisa e os respectivos resultados. Assim como sugestões de novas práticas de reutilização da casca do arroz encontradas em pesquisas.

\section{I perfil do gestor}

O gestor que respondeu é do gênero masculino, possui 41 anos, tem ensino superior completo, é bacharel em Administração e exerce a profissão de administrador no engenho. Trabalha na empresa há cerca de 15 anos e, atualmente, ocupa o cargo de Gerente de Produção.

\subsection{Dados relativos a produção e reutilização da casca do arroz}

Em relação a quantidade descascada de arroz, o entrevistado relatou que o engenho descasca 490 toneladas por mês e 5.880 toneladas por ano. Sobre o volume gerado de casca de arroz, na última colheita, a empresa produziu $5.800 \mathrm{Kg}$. A respeito da reutilização da casca do arroz, ele afirmou que a empresa utiliza o detrito na secadeira do arroz e em fornalhas. Além disso, a sobra da casca, ou seja, a parte que o engenho não ocupa internamente é retirada por empresas que reutilizam o resíduo na cama de aviários, em forno de olarias e em baia de cavalos. É importante mencionar que a casca é vendida por um valor simbólico de $\mathrm{R} \$ 5,00$ (cinco reais) a tonelada e é retirada por empresas terceirizadas, contratadas pelas adquirentes do resíduo. Pode-se citar, como exemplo de compradores: aviários dos municípios gaúchos, olarias e baias.

Muitas vezes, os próprios clientes, ou seja, os agricultores que vendem o arroz para que o engenho faça o beneficiamento e a comercialização, solicitam os detritos para colocarem em suas hortas. Sobretudo, por se tratar de fornecedores, o engenho faz a doação da casca para essas pessoas. As práticas mencionadas pelo entrevistado são apresentadas na figura 2
Conforme a figura 2 pode-se perceber que o referido engenho mantém atualmente três práticas para reutilização da casca de arroz, sem que essas representem algum retorno financeiro para a empresa.

Ao questionar o entrevistado se o engenho possui alguma ideia futura para melhor aproveitar o resíduo, ele disse "sim, pois os sócios pretendem reutilizar a casca para a geração de energia". A pergunta seguinte foi: $O$ processo de reutilização da casca do arroz é um dos exemplos referentes à Gestão Ambiental. Na sua percepção, o que é Gestão Ambiental? Obteve-se como resposta: "É ter cuidado com o que está acontecendo ao seu redor, ao meio em que interage e suas consequências e procurar minimizar ao máximo os danos, preservando o ambiente". Entretanto, embora o Instituto Rio Grandense do Arroz - IRGA tenha lançado em 2008 o selo de responsabilidade socioambiental, o entrevistado disse que o arroz comercializado pela empresa não contém em sua embalagem o selo verde.

No âmbito empresarial, é de extrema importância que as organizações se preocupem com os assuntos ecológicos, com a preservação ambiental. Tal atitude, de procurar alternativas de reutilização da casca, de modo que ela não seja jogada diretamente no meio ambiente, é um sinal próspero de crescimento nos negócios. Nota-se, conforme as palavras do Gestor que o lucro financeiro com a venda da casca do arroz não é tão expressivo. Porém, a empresa pode obter maior rentabilidade pelo fato de se preocupar com o meio ambiente, porque clientes conscientes estão optando por adquirir produtos que tenham uma rotulagem verde $\mathrm{ou}$, ao menos, priorizam por fazer compras em estabelecimentos comprometidos com a questão da responsabilidade ambiental.

\subsection{Perfil dos fornecedores}

Dentre os fornecedores que responderam o

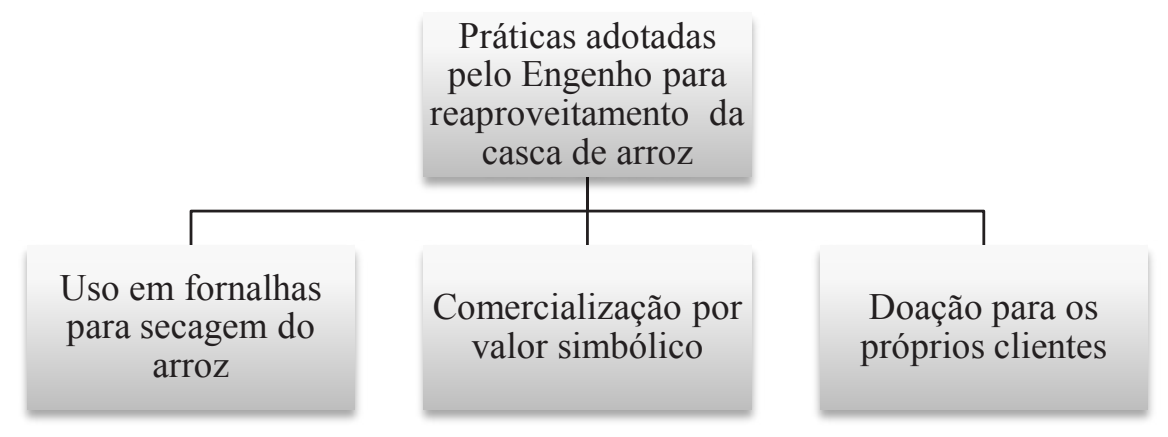

Figura 2 - Resumo das práticas de reutilização da casca de arroz adotadas pelo engenho Fonte: Elaborada pelos autores 
questionário, $58,75 \%$ dos indivíduos são do sexo masculino e $41,25 \%$ do sexo feminino. Após descrever a idade de todos os pesquisados, observa-se que a média da faixa etária foi de 46 anos. Um dos pesquisados possui 81 anos. Esta pessoa, embora na época ainda fosse criança, pode acompanhar o surgimento da empresa cuja criação data de 1938, com a montagem de um pequeno engenho de arroz.

Em relação ao grau de escolaridade, $38,75 \%$ cursaram o ensino fundamental incompleto, $15 \%$ estudaram até a oitava série, $13,75 \%$ não concluíram o ensino médio, $18,75 \%$ tem o ensino médio completo, $7,5 \%$ não concluíram o ensino superior e que $6,25 \%$ dos pesquisados possuem graduação.

Quando questionados sobre a profissão, 78,75\% dos pesquisados afirmaram ser agricultores(as), 16,25\% são donas de casa e 5\% estudantes. $\mathrm{O}$ menor índice correspondente à profissão foi de estudantes, pois a maior parcela dos pesquisados não são jovens.

Cabe ressaltar que todos os pesquisados moram no interior e, embora alguns optaram por uma formação no ramo da academia, eles(as) continuam no meio rural e buscam através da agricultura a sua sobrevivência.

\subsection{Percepção sobre Gestão Ambiental}

Em relação ao conhecimento sobre Gestão Ambiental, verifica-se que $77,5 \%$ já ouviram falar a respeito do assunto e $22,5 \%$ não tem conhecimento. Os pesquisadores tiveram a oportunidade de conversar com a maioria das pessoas pesquisadas. Deste modo, foi possível verificar que ainda há certo receio acerca do assunto, pois nem todos conseguiram perceber a importância das empresas como contribuintes para diminuir os impactos ecológicos.

Cabe salientar que a administração ou gestão do meio ambiente, ou simplesmente gestão ambiental, é entendida como "as diretrizes e as atividades administrativas e operacionais, tais como planejamento, direção, controle, alocação de recursos e outras realizadas com o objetivo de obter efeitos positivos sobre o meio ambiente" (BARBIERI, 2004, p.19).

\subsection{Conhecimento sobre a reutilização da casca de arroz}

Quando os pesquisados foram questionados se tinham conhecimento sobre o que era feito com a casca do arroz, 82,5\% afirmaram ter informações e $17,5 \%$ desconhecem o que está sendo feito com o resíduo. Já que sobrevivem da orizicultura, seria importante que os produtores de arroz soubessem as alternativas atribuídas para a reutilização dos resíduos do cereal que produzem. Sabe-se que existem inúmeras formas de reutilização, porém alguns não as conhecem.

Ao serem questionados se reutilizavam a casca do grão foi possível constatar que $70 \%$ reutilizam e que $30 \%$ não reutilizam a casca do cereal. Dentre os que reutilizam o resíduo destaca-se a utilização como adubo para hortas e pomares, como cama de aviários, no transporte de animais em caminhões, estrebarias e chiqueiros. A casca é utilizada ainda para substituir a lenha nos secadores de grãos, até mesmo, para a secagem do próprio arroz, ou seja, a queima do resíduo abastece as fornalhas e gera calor para secar os cereais. Além disso, é usada para cobrir o solo.

Analisando-se os achados da figura 3, percebe-se que os fornecedores do engenho que reutilizam a casca do arroz o fazem como práticas domésticas, ou seja, não visam lucros financeiros.

Analisando-se os achados da figura 3, percebe-se que os fornecedores do engenho que reutilizam a casca do arroz o fazem como práticas domésticas, ou seja, não visam lucros financeiros.

\subsection{Conhecimento sobre a destinação da casca de arroz pelo Engenho}

Sobre o conhecimento dos pesquisados sobre a destinação da casca de arroz dada pelo Engenho, $67,5 \%$ dos pesquisados responderam que sabem o que a empresa faz com a casca do cereal, destacando principalmente o uso nas fornalhas

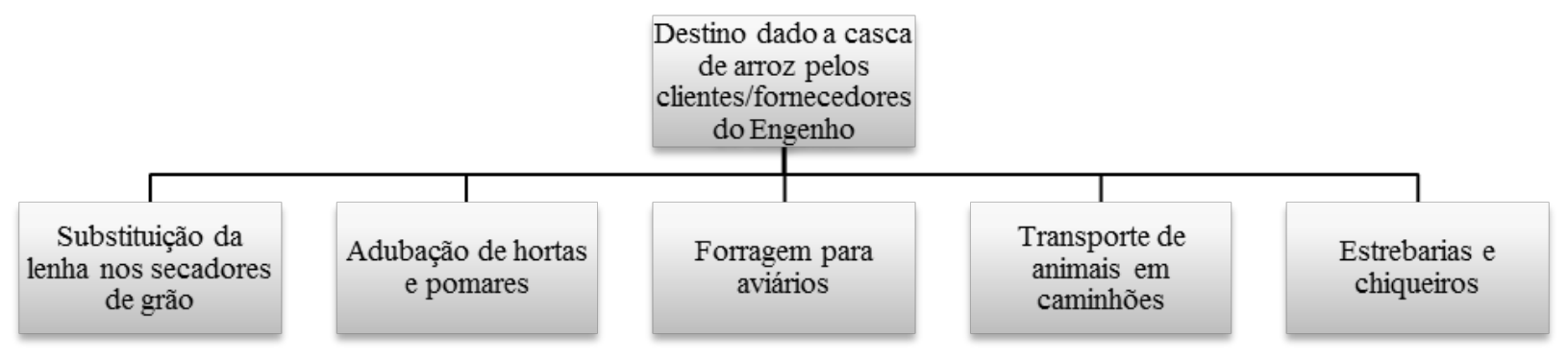

Figura 3-Reutilização da casca de arroz pelos clientes/fornecedores do Engenho

Fonte: Elaborada pelos autores 
para secagem do grão. Em contrapartida, 32,5\% não têm conhecimento sobre o que o engenho faz com o resíduo.

No que diz respeito ao processo de beneficiamento, 92,5\% dos pesquisados tinham conhecimento e $7,5 \%$ alegam não conhecer determinado reaproveitamento do resíduo. Nota-se que, embora todos sejam produtores de arroz, nem todos tem conhecimento sobre o que pode ser feito com os detritos desse grão. Contudo, é interessante apontar que houve contradições entre as respostas, pois $82,5 \%$ afirmaram ter conhecimento sobre o que é feito com a casca do arroz, e nesta questão 92,5\% citaram alguns processos de beneficiamento.

Os pesquisados que afirmaram conhecer certos reaproveitamentos, apontaram os seguintes: a casca é reaproveitada para produzir energia elétrica, utilizada em aviários, no transporte de gado. O resíduo é utilizado para fazer farelos e rações, usado em fornalhas de olarias, secadores de grãos, estufas de fumo. Reutilizada também como adubo orgânico para hortifrutigranjeiros, como componente na formação do cimento e inclusive, na utilizada na fabricação de móveis.

\subsection{Ideias para o reaproveitamento da casca do arroz}

Nem todos os entrevistados contribuíram com esta questão. Porém, a maioria das opiniões coletadas coincidiu com as respostas dissertativas mencionadas anteriormente e que já estão sendo praticadas. Outras possíveis utilidades da casca do arroz são apresentadas na tabela 1.

Evidencia-se no quadro 1 as inúmeras alternativas possíveis para usar a casca do arroz. Entretanto, deve-se destacar que o processo de reutilização é algo que, se estimulado, poderá ser bem aproveitado em diferentes segmentos. Neste sentido, percebe-se a importância das empresas em buscarem a criatividade, inovando cada vez

Tabela 1 - Ideias para o reaproveitamento da casca do arroz

\begin{tabular}{|c|c|c|}
\hline Fonte & Sugestões & Benefícios \\
\hline \multirow{6}{*}{$\begin{array}{l}\text { Produtores/fornecedores } \\
\text { pesquisados }\end{array}$} & $\begin{array}{l}\text { Reaproveitar a casca para a alimentação } \\
\text { humana. }\end{array}$ & Produção de farinha. \\
\hline & Isolamento térmico. & Acústica nas construções civis. \\
\hline & Adubo especial. & Para ser aplicado em grandes lavouras. \\
\hline & Produção de papel. & $\begin{array}{l}\text { Reduzir o desmatamento e diminuir ainda mais os } \\
\text { danos ecológicos. }\end{array}$ \\
\hline & Artesanatos e enfeites. & $\begin{array}{l}\text { Criatividade, para dar um toque de embelezamento } \\
\text { nos produtos. }\end{array}$ \\
\hline & Biodiesel. & $\begin{array}{l}\text { Ao contrário do petróleo, o resíduo do grão é uma } \\
\text { fonte renovável. }\end{array}$ \\
\hline \multirow{6}{*}{$\begin{array}{l}\text { Pesquisas em diversos } \\
\text { artigos }\end{array}$} & $\begin{array}{l}\text { Indústrias moveleiras na produção da } \\
\text { madeira MDF. }\end{array}$ & Lucro financeiro e ambiental. \\
\hline & $\begin{array}{l}\text { Produção de toras quadradas que servem } \\
\text { como lenha. }\end{array}$ & Minimiza o desmatamento. \\
\hline & $\begin{array}{l}\text { Produção de peças de carros (FERRO et al, } \\
\text { 2007). }\end{array}$ & $\begin{array}{l}\text { O uso da cinza da casca de arroz é constituída de } 96 \% \\
\text { de dióxido de silício substituindo talco na construção } \\
\text { de auto peças. Esses materiais são oriundos de jazidas } \\
\text { e correspondem a } 30 \% \text { dos componentes que formam } \\
\text { o para-choque dos automóveis. }\end{array}$ \\
\hline & Formar o cimento (SILVEIRA, 1996). & $\begin{array}{l}\text { Agregando ao concreto maior durabilidade e } \\
\text { resistência. }\end{array}$ \\
\hline & Combustível (ALMEIDA, 2010). & $\begin{array}{l}\text { Utilização para fins energéticos como outras } \\
\text { utilizações industriais pois apresenta uma pirolise } \\
\text { rápida. }\end{array}$ \\
\hline & $\begin{array}{l}\text { Fonte energética para termoelétricas } \\
\text { (MAYER, CASTELLANELLI e } \\
\text { HOFFMANN, 2007). }\end{array}$ & $\begin{array}{l}\text { Baixa poluição em relação à queima de outros } \\
\text { materiais. }\end{array}$ \\
\hline
\end{tabular}

Fonte: Elaborado pelos autores 
mais. A inovação se insere no mercado competitivo para suprir carências e atender os mais diversos desejos do consumidor. Todavia, esse poder de mudança está interligado com as questões ambientes, priorizando o resgate por ideias que atenuam a preservação do ecossistema.

A partir do exposto, procura-se salientar algumas alternativas de ganhos para as organizações. Tais sugestões inovadoras, além de adaptarem-se com um perfil de pessoas conscientes, proporcionam a sociedade um maior comprometimento e responsabilidade social. A casca do arroz, usada para substituir certas matérias-primas, é um exemplo de benefício, tanto para a comunidade quanto para o âmbito empresarial. A comunidade terá o meio ambiente menos poluído e as empresas terão agregado a sua marca uma consciência ecológica, além de adquirirem esta nova e eficaz matéria-prima por um custo menos elevado.

\section{CONSIDERAÇÕES FINAIS}

O mercado contemporâneo está em constante transição e as mudanças ocorrem diariamente. Para tanto, as empresas devem buscar medidas para superar tais desafios e para se manterem neste mercado altamente competitivo. A Gestão Ambiental, por sua vez, tem papel fundamental neste contexto, pois ela age como um fator que prolifera os avanços e as transformações na economia, na cultura e no desenvolvimento de uma nação. As empresas, atualmente, estão atentas a esta nova realidade e buscam oportunidades de ascensão nos negócios através da consciência ambiental. Inclusive, os consumidores se demonstram preocupados e interagem para minimizar os desequilíbrios do meio ambiente.

Conforme dados apresentados, é possível constatar que o setor orizícola está avançando, tanto em produtividade quanto em tecnologias e adaptações para uma maior produção do grão. Tal situação ocasionará uma elevada concentração de casca, oriunda do beneficiamento desse cereal. Isto é preocupante, pois nem todos os segmentos estão buscando alternativas para reutilizar estes detritos, que também podem servir como matéria-prima para certos produtos, ou seja, não utilizam essa fonte de renda.

Desta forma, o presente estudo teve como objetivo principal responder a seguinte problemática: Quais as alternativas de reutilização da casca do arroz, que podem gerar novas oportunidades de negócio para o Engenho de Arroz J. Fighera \& Cia. Ltda.? Constatou-se que o referido engenho mostra- -se preocupado com as questões ambientais e, por isso, já adota algumas medidas de reutilização da casca de arroz para não deixar os detritos expostos na natureza, tais como, reutilizar a casca para uso nas fornalhas da secadeira de grãos, doação para os próprios clientes/fornecedores do engenho e venda do restante do resíduo para empresas terceirizadas. Tais práticas demonstram que 0 Engenho em questão, apesar de possuir algumas estratégias de reutilização da casca de arroz, essas se mostram limitadas para uma geração efetiva de novas oportunidades de negócio. Assim, a partir dos resultados dessa pesquisa, foram identificadas algumas alternativas de comercialização, tais como, para a indústria alimentícia na produção de farinha, na produção de biodiesel, como material para isolamento acústico e no incremento da produção de cimento.

Sugere-se que a empresa faça parcerias com indústrias madeireiras, pois a casca do arroz também é componente da madeira MDF. Quanto a sugestão vinda do gerente de produção da empresa utilizar a casca para geração de energia elétrica, como a empresa ainda não produz uma elevada quantidade do resíduo capaz de abastecer uma hidrelétrica, não é viável para o momento. Sobretudo, esta opção de reutilização será uma grande oportunidade de crescimento quando o engenho beneficiar mais arroz.

Quando se mencionam os ganhos para a empresa, num primeiro momento se pensa em lucro. No entanto, não se pode restringir a este fato. Uma atitude consciente, como exemplo, responsabilizar-se com as causas ambientais, pode agregar mais valores do que simplesmente os financeiros. Este ganho vai além, pois a empresa tem a prospecção de ter sua marca renomada no mercado, de reter mais clientes, de se destacar entre o segmento em função da consciência ambiental. Entretanto, apesar de ter algumas práticas remeterem a uma preocupação ambiental na destinação dos resíduos do arroz, o engenho em questão não adotou o uso dos chamados "selos verdes", no caso o selo de responsabilidade socioambiental regulamentado desde 2008 e o selo ambiental da lavoura de arroz irrigado regulamentado em 2012.

Existem inúmeros incentivos governamentais que oferecem subsídios para as empresas buscarem processos inovadores relacionados à gestão ambiental. Da mesma forma, à medida que ele contribui para aumentar a oferta de produtos e serviços, deve continuar incentivando as organizações, a população e a sociedade em geral a pensarem e praticarem ações conjuntas em prol do meio ambiente. Ratifica-se que as indústrias são 
as maiores poluentes do planeta. Por isso, devem dar o exemplo e inovarem também na dimensão ambiental.

Enfim, a preocupação ambiental, cuja temática deste estudo deu enfoque ao processo de reutilização da casca do arroz, é um dos passos fundamentais para toda empresa que almeja a eficácia, a excelência organizacional e que deseja ser referência na sociedade moderna.

Para estudos futuros, sugerem-se pesquisas sobre a gestão ambiental e novas alternativas de reutilização da casca do arroz realizando estudos de casos em diferentes cooperativas de grãos e engenhos de arroz. Percebe-se que ainda há muito a se evoluir para diminuir os problemas ambientais. A empresa J. Fighera \& Cia. Ltda. já está contribuindo para este processo de revitalização. Entretanto, cabe a todos os outros segmentos ingressarem o quanto antes.

\section{REFERÊNCIAS}

ALMEIDA, S. R. Pirólise Rápida de Casca de Arroz: estudo de parâmetros e caracterização de produtos. 2010. Dissertação (Mestrado em Ciência dos Materiais) - Universidade Federal do Rio Grande do Sul, Porto Alegre, 2010. Disponível em: <http://www. lume.ufrgs.br/handle/10183/29714>. Acesso em: 16/12/2013.

ANDRADE, R. O. B.; TACHIZAWA, T.; CARVALHO, A. B. Gestão Ambiental - Enfoque Estratégico Aplicado ao Desenvolvimento Sustentável. São Paulo: Pearson Makron Books, 2002.

\section{ATLAS SÓCIOECONÔMICO RIO GRANDE}

DO SUL. SEPLAG - Secretaria de Planejamento, Gestão e Participação Cidadã. Disponível em: <http://www.scp.rs.gov.br/atlas/conteudo. asp?cod_menu_filho $=819 \&$ cod_menu $=817 \&$ tipo meme $=$ ECONOMIA\&cod_conteudo $=1490>$. Acesso em: 18/05/2013.

BAKER, M. J. Administração de Marketing: conceitos revistos e atualizados. Rio de Janeiro: Campus, 2005.

BARBIERI, J. C. Gestão Ambiental Empresarial: conceitos, modelos e instrumentos. São Paulo: Saraiva, 2004.

BULOS, U. L. Constituição Federal Anotada. São Paulo: Saraiva, 2003.
CERVO, A. L.; BERVIAN, P. A.; SILVA, R. Metodologia Científica. São Paulo: Pearson Pretince Hall, 2007.

\section{COIMBRA, J. A. A. O Outro Lado do Meio}

Ambiente. São Paulo: Cetesb, 1985.

CONAB. Disponível em: < http://www.conab.gov. br/conabweb>. Acesso em: 28/11/2011.

DEMO, P. Introdução à metodologia da ciência. São Paulo: Atlas, 1987.

DIAS, R. Gestão Ambiental: responsabilidade social e sustentabilidade. São Paulo: Atlas, 2006.

DONAIRE, D. Gestão Ambiental na Empresa. São Paulo: Atlas, 2009.

DRUCKER, P. F. Inovação e Espírito Empreendedor. São Paulo: Pioneira, 2000.

FERRO, W. P.; SILVA, L. G. A.; WIEBECK, H. Uso da Cinza da Casca do Arroz como Carga em Matrizes de Poliamida 6 e Poliamida 6.6. Polímeros: Ciência e Tecnologia, vol. 17, n 3, p. 240-243, 2007

FURASTÉ, P. A. Normas Técnicas para o Trabalho Científico: elaboração e formatação. Explicitação das Normas da ABNT. Porto Alegre: s.n, 2008.

GIL, A. C. Projetos de Pesquisa. São Paulo: Atlas, 1996.

Como elaborar projetos de pesquisa.

São Paulo: Atlas, 2008.

INSTITUTO BRASILEIRO DE GEOGRAFIA E ESTATÍSTICA - IBGE. Disponível em: <http:// www.ibge.gov.br/home/estatistica/pesquisas/pesquisa_resultados.php?id_pesquisa $=4>$. Acesso em: 19/05/2013.

INSTITUTO BRASILEIRO DE GEOGRAFIA E ESTATÍSTICA - IBGE. Levantamento sistemático da produção agrícola. 2012. Disponível em: <http:// www.ibge.gov.br/home/estatistica/indicadores/ agropecuaria/1spa/1spa_201202.pdf>. Acesso em: 19/05/2013.

KIMBERLY, J. R.; EVANISKO, M. J. Organizational innovation: the influence of individual, organizational, and contextual factors on hospital adoption of technological and administrative innovations. USA: Academy of Management Journal, 1981. 
KOTLER, P. Marketing de A a Z: 80 conceitos que todo profissional precisa saber. Rio de Janeiro: Campus, 2003.

LAKATOS, E. M.; MARCONI, M. A. Metodologia do trabalho científico: procedimentos básicos, pesquisa bibliográfica, projeto e relatório, publicações e trabalhos científicos. São Paulo: Atlas, 2007.

MARTINS, J.; BICUDO, M. A. V. A pesquisa qualitativa em Psicologia: fundamentos e recursos básicos. São Paulo: Vozes, 1994.

MAYER, F. D.; CASTELLANELLI, C.; HOFFMANN, R. Geração de Energia através da Casca de Arroz: uma análise ambiental. In: XXVII ENCONTRO NACIONAL DE ENGENHARIA DE PRODUÇÃO, 2007, Foz do Iguaçu. Anais... Foz do Iguaçu: Associação Brasileira de Engenharia de Produção, 2007. Disponível em: <http://www.abepro. org.br/biblioteca/ENEGEP2007_TR650480_0007. Pdf>. Acesso em: 02/06/2013.

MINISTÉRIO DA AGRICULTURA. Disponível em: <http://www.agricultura.gov.br/vegetal/culturas/arroz>. Acesso em: 21/05/2013.

OLIVEIRA, S. L. Tratado de Metodologia Científica: projetos de pesquisas, TGI, TCC, monografias, dissertações e teses. São Paulo: Pioneira Thomson Learning, 2001.

PESKE, S. T.; NEDEL, J. L.; BARROS, A. C. S. A. Produção de Arroz Irrigado. Pelotas: Universidade Federal de Pelotas, 1998.

PHILIPPI Jr., A.; PELICIONI, M. C. F. Educação Ambiental e Sustentabilidade. São Paulo: Manole, 2005.

REVISTA CAMPO ABERTO. Massey Ferguson. Ed. 96, Junho 2009.

REVISTA LAVOURA ARROZEIRA. Porto Alegre: IRGA. Volume 57, N 450, Set/2009.

RICHARDSON, R. J. Pesquisa social: métodos e técnicas. São Paulo: Atlas, 1999.

SEVERINO, A. J. Metodologia do Trabalho Científico. São Paulo: Cortez, 2007.

SILVEIRA, A. A. A Utilização de Cinza de Casca de Arroz com Vistas a Durabilidade de Concre- tos: estudo do ataque por sulfatos. 1996. Dissertação (Mestrado em Engenharia) - Universidade Federal do Rio Grande do Sul, Porto Alegre, 1996. Disponível em: <http://www.lume.ufrgs.br/handle/10183/3468>. Acesso em: 02/06/2013.

TACHIZAWA, T. Gestão Ambiental e Responsabilidade Social Corporativa: estratégias de negócios focadas na realidade brasileira. São Paulo: Atlas, 2009.

ROGERS, E. M.; SHOEMAKER, F. F. Qv': sawroach. New York: The Free Press, 1971.

WHIPP, R.; CLARK, P. Innovation and the auto industry: Product, process and work organization. London: Francis Pinter, 1986. 